Article

\title{
An Analysis of Decoupling and Influencing Factors of Carbon Emissions from the Transportation Sector in the Beijing-Tianjin-Hebei Area, China
}

\author{
Xiaoping Zhu and Rongrong $\mathrm{Li}^{*}$ \\ School of Economic \& Management, China University of Petroleum (Huadong), No. 66 West Changjiang Road, \\ Qingdao 266580, China; zhuxpyj@163.com \\ * Correspondence: lirr@upc.edu.cn; Tel.: +86-0532-8698-1324 \\ Academic Editor: John Barrett \\ Received: 24 March 2017; Accepted: 26 April 2017; Published: 30 April 2017
}

\begin{abstract}
The transport sector is the major green-house gas emitter and most rapidly growing sector in terms of consuming energy in China. Understanding the driving forces behind carbon emission is a prerequisite for reducing carbon emissions and finding a balance between economic growth and carbon emissions. The purpose of this paper is to identify the impact of the factors which influence the level of carbon emissions from the transportation sector in the Beijing-Tianjin-Hebei (BTH) area, China, using decomposition model, combined with a decoupling elasticity index. The results of our study indicate that: (1) changes in the level of carbon emissions from the transportation sector are not always synchronized with changes in economic growth. (2) The decoupling state between the carbon emissions and economic growth of Tianjin and Beijing can be roughly divided into two phases. The first phase was during the 2005 to 2009 period, when the decoupling state was pessimistic. The second phase was from 2009 to 2013, when the decoupling state became better overall and was mainly dominated by weak decoupling. Conversely, the decoupling state of Hebei was mainly weak during this period. (3) Economic growth and population size play positive roles in increasing the levels of transportation-related carbon emissions in BTH. However, the energy structure is a negative force. The effect of energy intensity always plays a negative role in Tianjin and Hebei, but positive in Beijing. The industrial structure effect shows a fluctuating trend, but the cumulative effect value is negative, and negative interaction is prominent. Finally, this paper gives some suggestions on how to develop low-carbon transport in BTH area.
\end{abstract}

Keywords: decoupling analysis; transportation sector; Logarithmic Mean Divisia Index Method; influencing factors; Beijing-Tianjin-Hebei (BTH) area

\section{Introduction}

Today, the carbon emissions issue has become a bottleneck which is restricting the development of the global economy and society as a whole [1-4]. Carbon currently contributes approximately $63 \%$ of the gaseous radiative force contributing to climate change, as reported by the IPCC [5]. Due to rapid economic development and accelerated urbanization, the transport sector has experienced dramatic growth that in turn has led to excessive demand for fossil fuel energy forms. Oil consumption and carbon dioxide emissions in the transportation sector account for approximately $50 \%$ and $25 \%$ of global totals, respectively [6]. In 2002, the Organization for Economic Co-operation and Development (OECD) predicted that the carbon emissions resulting from transport will double by 2020 (compared with 1990 levels) unless appropriate action is taken [7]. As a large consumer of energy, China has committed itself to lowering the carbon intensity of GDP by from $40 \%$ to $45 \%$ (below 2005 levels) by $2020[8,9]$. This commitment was made at the Copenhagen Climate Change Conference in 2009. Faced 
with the pressure of this commitment, China has clearly now realized the importance of reducing carbon emissions [10-13].

Over the last several decades, the transport sector in China has not just been the major oil consumer and green-house gas emitter, but transport has also been the fastest growing sector in terms of energy demand and green-house gas emissions [14]. The transport sector has now become the third largest carbon emission source, after the energy and industry sectors [15-18]. The Beijing-Tianjin-Hebei (BTH) area, also known as the Jinginiji Economic Band, is located in northern China and includes two municipalities (Beijing and Tianjin) and one province (Hebei) [19-21]. Today, BTH is one of the most economically vibrant regions and simultaneously one of China's major traffic hubs. In 2011, BTH generated more than $10 \%$ of the total national GDP, in the process becoming one of the busiest and most comprehensive transport areas in China [22]. In summary, analysis of the decoupling and influencing factors of carbon emissions from the transportation sector in the BTH area is very important in terms of reducing carbon emissions.

\section{Literature Review}

The issue of carbon emissions is one of common concern on a global level. A great many studies have focused on reducing carbon emission all over the world. Some studies have taken the US as an example, exploring the carbon emissions from different sources, such as land-use change [23-26], farm operations [27], agriculture and forestry [28], and international trade [29]. Lugauer [30] estimated the impact of age distribution on carbon dioxide emissions from 1990 to 2006 , by examining demographic variations in a panel consisting of 46 countries. Birgit Friedl [31] explored the relationship between economic growth and carbon dioxide emissions in Austria. Taking China as an example, Wei et al. [32] considered emissions abatement across China. Yang et al. [33] analyzed the allocation of carbon intensity reduction targets by 2020, as applied to different industrial sectors in China. China appears to be paying close attention to the need to reduce the levels of carbon emissions [11,13,34-38]. Fei, Wang, et al. [39] analyzed the driving forces behind carbon emissions caused by energy consumption in Guangdong Province.

In addition, researchers have carried out plenty of work related to lowering the carbon emission levels of the transportation sector at a national level. Taking the countries or regions (except China) as an example, Houda Achour and Mounir Belloumi [14] applied the Logarithmic Mean Divisia Index Method (LMDI) to identify the influencing factors and to measure each factor's corresponding contributions to the energy consumption of the transportation sector in Tunisia during the years from 1985 to 2014. This study's major discoveries were as follows: The effect of economic output, transportation intensity, population scale, and transportation structure were the most important factors contributing to the growth of carbon emissions. Conversely, the effect of energy intensity contributed significantly to decreasing the emissions. Chandran and Tang [40] found that energy consumption in the road transportation sector significantly contributes to environmental pollution (particularly $\mathrm{CO}_{2}$ emissions) in Malaysia [41]. Ong et al. [42] maintained that the transportation sector is contributing to a growing share of carbon emissions in Malaysia. Steenhof et al. [43] explored the determinants of the greenhouses emissions caused by freight transport. This study used a decomposition analysis. Marco Mazzarino [44] identified the factors determining the variety of carbon dioxide emissions in Italy's transport sector, thus evaluating the impact of that nation's transport sector in terms of global warming. Mraihi et al. [45] adopted the LMDI method to identify the driving factors of energy consumption changes for road-based modes of transport over the period from 1990 to 2006 [14]. The fact is, $\mathrm{CO}_{2}$ emissions are just one type of pollution emissions. Some papers tend to use the term pollution emissions to refer to $\mathrm{CO}_{2}$ emissions. Many empirical studies on the relationships between economic growth and environmental pollution have also been conducted in France [46], South Africa [47], Turkey [48], and Malaysia [49].

Taking China as an example, Dai et al. [16] analyzed the critical factors that brought about the changes in logistics energy consumption in China during the period from 1980 to 2010. Dai's study 
used the Logarithmic Mean Divisia Index (LMDI) method. The study's results showed that logistics activities, transportation modes and transportation intensity all play positive roles in increasing the levels of energy consumptions of the logistics sector. However, improvements in energy intensity significantly inhibited the rise in energy use in China's logistics industry. Wang et al. analyzed the energy consumption status facing China [50-53]. Zhang et al. [54] revealed the factors influencing the changes in transportation energy consumption by also using the LMDI method. Lin et al. [17] adopted a quantile analysis to discuss the impact of GDP per capita (gross domestic product), energy intensity, carbon intensity, and total population on the carbon emissions of China's transportation sector over the period from 1980 to 2010. The key finding of Lin's study was that GDP, energy intensity, and carbon intensity had a greater influence on carbon emissions than did urbanization. In general, many studies have revealed that the decline in energy intensity has been the main factor associated with emissions deceleration in China [55]. S. Qipeng [56] identified the driving factors behind energy consumption and measured each factor's corresponding contributions in terms of energy consumption. In this paper, the driving factors are divided into scale effect, structure effect and technique effect, according to the driving mechanism. Many empirical studies that discuss the relationships and linkages between economic growth, energy consumption and environmental pollution have been conducted in different regions [57]. Some studies have also measured environmental and energy performance in China $[11,13,58-60]$ and have also conducted a comparative analysis of China's regional energy and emissions performance [60-62] using a DEA model. Zhao et al. [63] performed a complete decomposition and decoupling analysis, in order to quantitatively analyze the main factors influencing the carbon emissions of the transportation (TCE) sector in Guangdong Province over the period from 1995 to 2012. Zhao's results indicated that the decoupling degree between transportation output and TCE was relatively low. Optimization of tertiary industry structures played an inhibition role in the TCE, while the rapid growth of both per capita GDP and the population played a boosting role in the TCE, which in turn directly led to the elasticity index rising. The decoupling state was weak decoupling initially, but this improved significantly after 2005. Through their research, Zhao's team found that the decoupling state presents as a five-year periodic pattern of fluctuations, which may in turn be influenced by China's national five-year plans. However, the impact from energy and other internal drivers can be reduced.

A number of studies have already attempted to examine the determinants of $\mathrm{CO}_{2}$ emissions. These studies have mostly focused on the aspect of specific countries or representative provinces. However, studies at the regional level are rare. At present, the development of the BTH economic circle is the focus of many researchers. The BTH region is the largest and enjoys the highest level of development of any region in the economic core area of northern China. Also, BTH is an important hub and gateway of our country with regard to international economic exchanges and cooperation. However, BTH is also one of the worst areas for transportation-related carbon emissions. Recently, many scholars have studied the issue of integrating the transportation sectors of Beijing, Tianjin and Hebei. However, few scholars have paid much attention to the carbon emissions from the transportation sector in the BTH economic circle. To summarize, researching the issue of carbon emissions from the transportation sector in the BTH area is hugely significant. As mentioned earlier, our work builds on the work of previous studies. Our study also makes an original contribution, by taking the BTH area as an example and by extending the conventional decomposition practice to explore the influencing factors of carbon emissions in the transportation sector.

Considering the availability of statistical data, this paper employs the data of the transportation sectors in Beijing, Tianjin and Hebei, from 2005 to 2013. Our study also applies a Tapio decoupling model and LMID decomposition method to study the driving factors and decoupling effects of the transportation sector's carbon emissions. This article aims to solve the following questions: (1) Are the current changes in carbon emission levels in accordance with the changes in the increased output of the transportation sector? (2) Does higher output produce more carbon emissions in the transportation sector? If not, what is the decoupling degree between carbon emissions and economic growth in 
the transportation sector? (3) What factors influence the levels of carbon emissions coming from the transportation sectors in Beijing, Tianjin and Hebei?

This paper is organized as follows: Section 2 proposes an overview of the related work on decoupling analysis and decomposition analysis. Section 3 describes the methodology and data used in this research. Section 4 presents the results of both the decoupling analysis and decomposition analysis. Finally, the conclusions and summary of this study are presented in Section 5.

\section{Methodology and Data}

\subsection{Methodologies}

\subsubsection{Calculation the Carbon Emission in Transportation Sector}

At present, two methods are used to calculate the carbon emissions of the transportation sector: (1) The top-down approach. We can calculate the carbon emissions based on the energy consumption of vehicles, multiplied by the carbon emission factors of various energies. (2) The bottom-up approach. We can calculate the carbon emissions based on the mileage and energy consumption per travelling mile of different traffic types and the number of vehicles on the road. The "bottom-up" approach has a distinct disadvantage. The relevant data may have large errors, and data collection is difficult. Comparatively speaking, the data is more accurate when using the top-down approach. Therefore, in this paper, the top-down approach is used to calculate the transportation-related carbon emissions in BTH. According to the IPCC method of greenhouse gas emission inventories $[9,64]$, carbon emissions can be estimated via the Equation (1):

$$
\mathrm{C}=\sum_{i} E_{i} \times F_{i} \times K_{i}
$$

where $C$ denotes the total carbon emissions of the transportation sector; $E_{i}$ is the consumption of the $i$ th fuel; $F_{i}$ is the conversion coefficient of standard coal of the $i$ th fuel, and $K_{i}$ is the carbon emission factor of the $i$ th fuel. The carbon emission coefficient factor of coal, petroleum and natural gas are 0.7329 , 0.5574 and 0.4226 , respectively [65]. In order to ensure the comparability of the data, all fuels should be converted into standard coal. The conversion coefficient of standard coal references is found in Table 1 . According to the study by Yang et al. [66], we know that heat and electricity cannot directly generate carbon emissions. As such, we do not calculate them here. The conversion coefficient of standard coal of diverse fuels is based on the GHG Protocol Tool for Energy Consumption in China [67] as follows:

Table 1. The conversion coefficient of standard coal of diverse fuels.

\begin{tabular}{cccc}
\hline Fuel & Fi (tce/t) & Fuel & Fi (tce/t) \\
\hline Raw coal & 0.7143 & Diesel oil & 1.4571 \\
Gasoline & 1.4714 & Fuel oil & 1.4286 \\
Kerosene & 1.4714 & Natural gas & 12.1430 tce $/ 10^{4} \mathrm{~m}^{3}$ \\
\hline
\end{tabular}

tce denotes ton of standard coal equivalent.

\subsubsection{Tapio Decoupling Evaluation Model}

The term "decoupling" means the connection between environmental stress and economic variations has been broken. According to the OECD report, decoupling usually describes the relationship between changes in the percentage of carbon emissions and the corresponding changes in the transportation sector's percentage of GDP. The decoupling model proposed by Tapio is based on the developing of an OECD decoupling model. This model is widely used to analyze the relationship between economic growth and carbon emissions [60,68-70]. For example, the decoupling model was applied very early on to analyze the relationship of economic growth and transport volume in transportation fields [71]. 
We can construct the decoupling model of the carbon emissions of the transportation sector as follows:

$$
\mathrm{e}(\mathrm{C}, \mathrm{G})=\frac{\frac{\Delta C}{\mathrm{C}}}{\frac{\Delta G}{G}}=\frac{\% \Delta \mathrm{C}}{\% \Delta \mathrm{G}}
$$

where $\mathrm{e}(\mathrm{C}, \mathrm{G})$ represents the decoupling index of carbon emissions and GDP in the transportation sector, and $\% \Delta \mathrm{C}$ and $\% \Delta \mathrm{G}$ indicate the changes in the percentage of carbon emissions and the transportation sector's GDP, respectively. The degrees of decoupling between transportation-related carbon emissions and transportation sector GDP are divided into eight types, namely (1) strong decoupling, (2) weak decoupling, (3) recessive decoupling, (4) expansive coupling, (5) recessive coupling, (6) strong negative decoupling, (7) weak negative decoupling and (8) expansive negative decoupling. Of these varying degrees, strong decoupling is the optimum state in which to realize the goal of low-carbon transportation and meet the requirement of a low-carbon economy. In contrast, strong negative decoupling is the worst state. Strong negative decoupling is not conducive to the sound and sustainable development of the transportation sector. The classification and evaluation criteria for these eight decoupling states are as shown in Figure 1 [70].

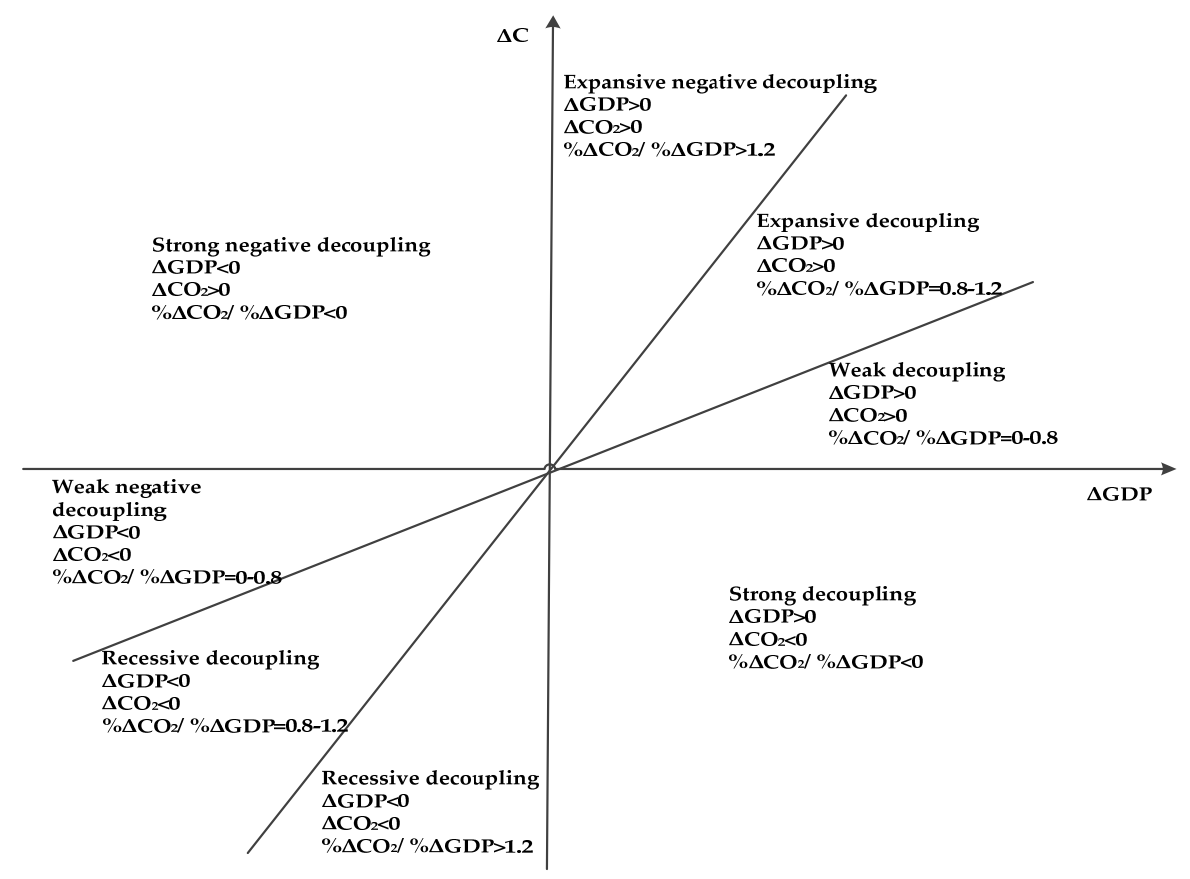

Figure 1. Classification and evaluation criteria for decoupling states.

\subsubsection{The Logarithmic Mean Divisia Index (LMDI) Model}

The Kaya Identities was first proposed by Yoichi Kaya [64]. This method is used to divide the carbon emissions into the products of different influencing factors, including the population, GDP per capita, GDP energy intensity and carbon emission intensity. The equation is expressed as follows:

$$
C=\mathrm{P} \times \frac{G D P}{P} \times \frac{E}{G D P} \times \frac{C}{E}
$$

where $P$ is the population, GDP/P is the GDP per capita, E/GDP is GDP energy intensity and C/E represents carbon emission intensity.

The LMDI decomposition method is one of the main research methods used to examine the influencing factors of carbon emissions. The basic idea of LMDI is to decompose the changes in a target variable into a combination of several influencing factors. This is done so that we can identify the degree of the influence of each factor, that is, the contribution rate. The result of the LMDI method 
does not produce residuals. Therefore, LMDI is a relatively superior decomposition method [72-79]. This paper uses the LMDI method to analyze the influencing factors of carbon emissions in the transportation sector of North China. The LMDI method can be expressed as an extended Kaya identity, whereby the carbon emissions in the transportation sector can be decomposed as follows:

$$
\begin{aligned}
\mathrm{Co}_{2}= & \sum_{i} \frac{C_{i}}{E_{i}} \times \frac{E_{i}}{E} \times \frac{E}{G} \times \frac{G}{G D P} \times \frac{G D P}{P} \times P \\
& =\sum_{i} f_{i} \times s_{i} \times e \times u \times g \times p
\end{aligned}
$$

The meaning of each variable is as shown in Table 2.

Table 2. The meaning of each variable in LMDI model.

\begin{tabular}{cc}
\hline Variable & Meaning \\
\hline$C i$ & Carbon emissions of the ith fuel type \\
$E i$ & The ith fuel consumption \\
$G$ & The total primary energy consumption \\
$G D P$ & GDP in the transportation sector \\
$P$ & The gross domestic product \\
$f i$ & $f_{i}=C_{i} / E_{i}$ It is the carbon emissions of the $i$ th fuel type. That is the carbon emission coefficient factor. \\
$s i$ & $S_{i}=E_{i} / \mathrm{E}$ It is the total energy consumption share of the ith fuel type in the transportation sector. \\
& That is the energy structure factor. \\
$e$ & $e=\mathrm{E} / \mathrm{G}$ It is the energy consumption per unit GDP in transportation sector. That is energy intensity factor. \\
$g$ & $u=\mathrm{G} / \mathrm{GDP}$ It is the GDP in the transportation sector weight in GDP. That is industrial structure factor. \\
$p$ & $g=\mathrm{G}^{\prime} / \mathrm{P}$ It is the GDP per capita. That is economic growth factor. \\
\hline
\end{tabular}

As can be clearly seen from Table 2, the carbon emissions in the transportation sector are divided into six separate factors, namely (1) the carbon emission coefficient factor, (2) transportation energy structure factor, (3) transportation energy intensity factor, (4) industrial structure factor, (5) economic growth factor and (6) the population size factor. The difference in the levels of carbon emissions in the transportation sector between the base period and the $t$ period is called the cumulative effects $\Delta \mathrm{C}$. Also, $\Delta \mathrm{C}$ refers to the total changes in carbon emissions, and $\Delta \mathrm{C}$ consists of 6 parts, namely (1) carbon emission intensity effect $\Delta C_{f}$, (2) energy structure effect $\Delta C_{s}$, (3) energy intensity effect $\Delta C_{e}$, (4) industrial structure effect $\Delta C_{u}$, (5) economic growth effect $\Delta C_{g}$, and (6) population size effect $\Delta C_{p}$. These represent the contribution of each factor to the changes in traffic carbon emissions, that is:

$$
\Delta C=C(t)-C(0)=\Delta C_{f}+\Delta C_{s}+\Delta C_{e}+\Delta C_{u}+\Delta C_{g}+\Delta C_{p}
$$

The results after using the LMDI decomposition method are as follows:

$$
\begin{aligned}
\Delta C_{f} & =\sum_{i} W_{i} \times \ln \frac{f_{i}(t)}{f_{i}(0)} \\
\Delta C_{s} & =\sum_{i} W_{i} \times \ln \frac{S_{i}(t)}{S_{i}(0)} \\
\Delta C_{e} & =\sum_{i} W_{i} \times \ln \frac{e(t)}{e(0)} \\
\Delta C_{u} & =\sum_{i} W_{i} \times \ln \frac{u(t)}{u(0)} \\
\Delta C_{g} & =\sum_{i} W_{i} \times \ln \frac{g(t)}{g(0)}
\end{aligned}
$$




$$
\begin{gathered}
\Delta C_{p}=\sum_{i} W_{i} \times \ln \frac{p(t)}{p(0)} \\
W_{i}=\frac{\left(C_{i}(t)-C_{i}(0)\right)}{\left(\ln _{i}(t)-\ln _{i}(0)\right)}
\end{gathered}
$$

Generally, the carbon emission coefficients of all types of fossil fuels are fixed. Therefore, the factors affecting transportation in BTH are mainly the energy structure, energy intensity, industrial structure, economic growth and population size.

\subsection{Data Sources}

In this paper, the data pertaining to the consumption of coal, gasoline, kerosene, diesel oil and fuel oil in the BTH transportation sector were collected from energy balance tables in previous China Energy Statistical Yearbooks [80-82]. In the process of calculation, the GDP, total output value of the transportation sector and the total population of every province are derived from the database of China's economic and social development. In order to ensure the accuracy of comparison, economic output values in the transportation sectors of various provinces are converted based on the year 2005. In this paper, the minority conversion coefficients of the 2009 transportation sector GDP Indexes of Tianjin and Hebei are missing. We used the average annual growth rate of the known GDP Index to estimate the missing minority conversion coefficients of the 2009 GDP Index of Tianjin and Hebei.

\section{Analysis Results}

\subsection{Economic Output Values and Carbon Emissions of the Transportation Sector}

The output values of each province's transportation sector from 2005 to 2013 are shown in Figure 2. From this figure, we can see that an approximate linear relationship exists between the economic output values of each province's transportation sector, and time. Among all values, the output value of Hebei holds first place, expanding at an average of $10.38 \%$ per year. The economic output values from the transportation sector of Beijing and Tianjin hold second and third place, respectively. Their values expanded at an average of $7.03 \%$ and $11.17 \%$ per year.

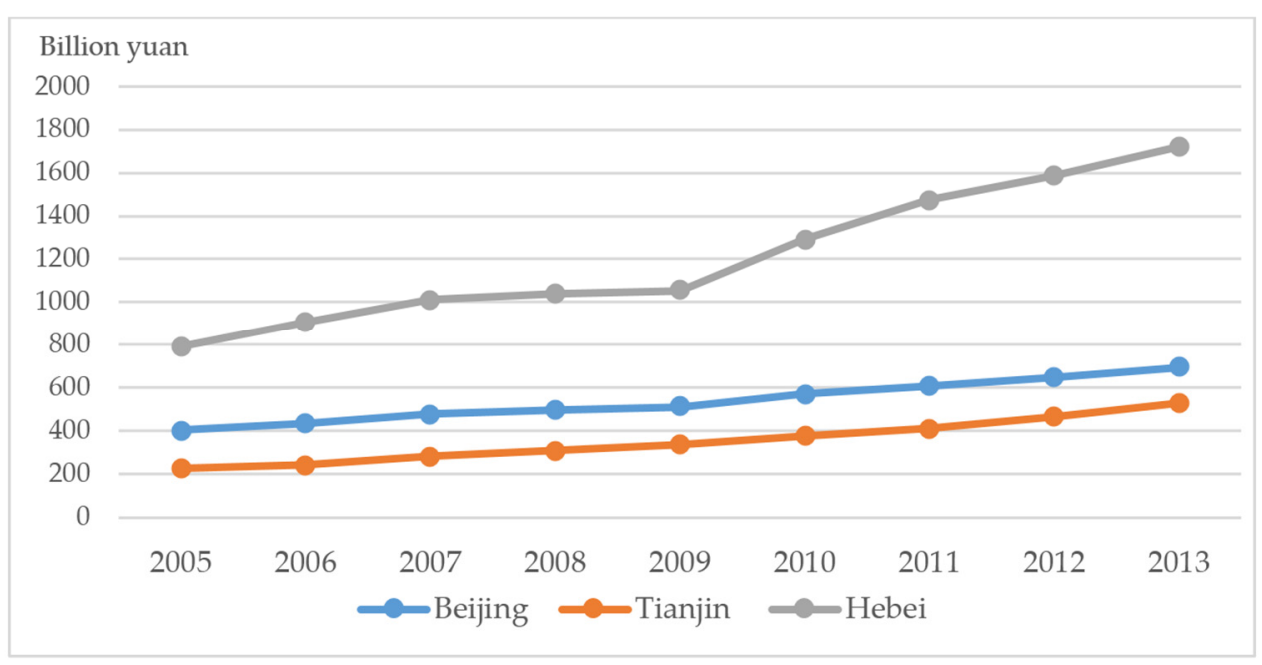

Figure 2. Economic output values of transportation sector in Beijing-Tianjin-Hebei area.

According to Equation (1) and the energy consumption of the BTH transportation sector, the amount of carbon emissions in the transportation sector from 2005 to 2013 was calculated (see Figure 3). From this figure, we can see that the carbon emissions of Tianjin's transportation sector were less than those of Beijing and Hebei during the study period. The carbon emissions of 
the transportation sector in Beijing were less than those of Hebei from 2005 to 2007, while Beijing's emissions were more than those of Hebei from 2007 to 2013. From 2005 to 2013, the average annual growth rate of the carbon emissions of the transportation sectors in Beijing, Tianjin, and Hebei were $10.11 \%, 2.57 \%$ and $4.39 \%$, respectively. We can use the available information to calculate that the growth rate of transportation-related carbon emissions in Beijing is significantly higher than those of Tianjin and Hebei.

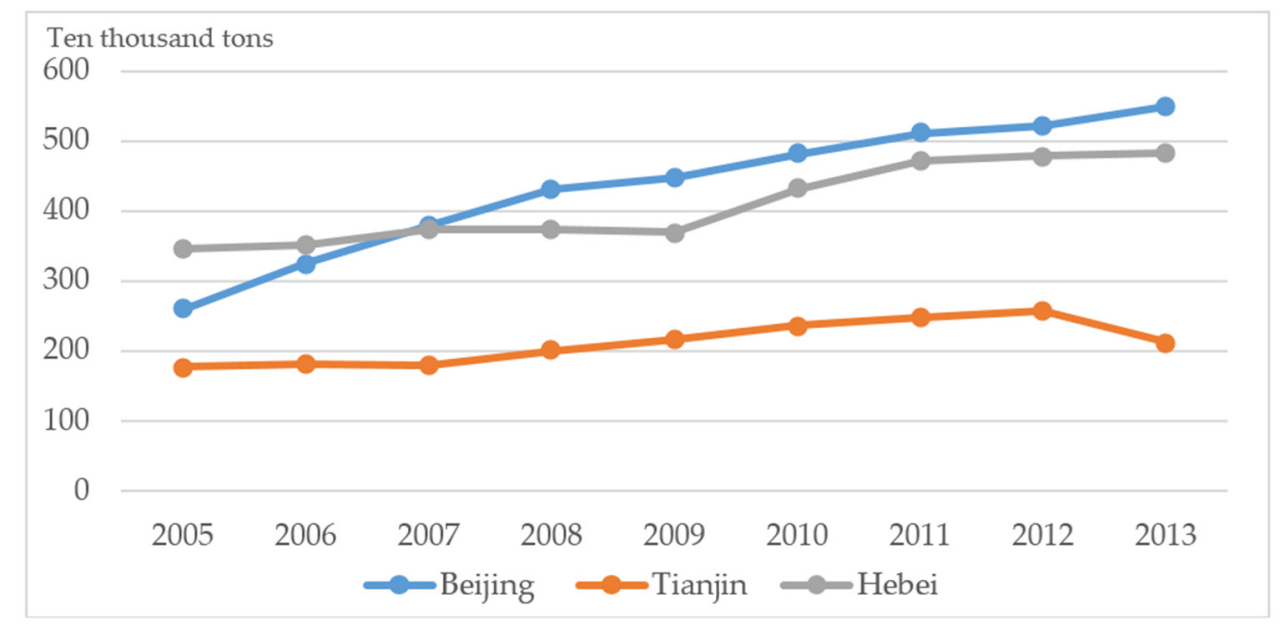

Figure 3. Carbon emissions from transportation sector in Beijing-Tianjin-Hebei area.

\subsection{Decoupling State in the Transportation Sector}

During the study period, both similarities and differences existed between the decoupling states of different provinces, as shown in Table 3.

Table 3. The decoupling state of the Beijing-Tianjin-Hebei area.

\begin{tabular}{|c|c|c|c|}
\hline Year & Beijing & Tianjin & Hebei \\
\hline 2005-2006 & $\begin{array}{c}3.33 \\
\text { (Expansive negative decoupling) }\end{array}$ & $\begin{array}{c}0.36 \\
\text { (Weak decoupling) }\end{array}$ & $\begin{array}{c}0.13 \\
\text { (Weak decoupling) }\end{array}$ \\
\hline 2006-2007 & $\begin{array}{c}1.72 \\
\text { (Expansive negative decoupling) }\end{array}$ & $\begin{array}{c}-0.09 \\
\text { (Strong decoupling) }\end{array}$ & $\begin{array}{c}0.53 \\
\text { (Weak decoupling) }\end{array}$ \\
\hline 2007-2008 & $\begin{array}{c}3.38 \\
\text { (Expansive negative decoupling) }\end{array}$ & $\begin{array}{c}1.20 \\
\text { (Expansive negative decoupling) }\end{array}$ & $\begin{array}{l}-0.12 \\
\text { (Strong decoupling) }\end{array}$ \\
\hline 2008-2009 & $\begin{array}{c}1.28 \\
\text { (Expansive negative decoupling) }\end{array}$ & $\begin{array}{c}0.89 \\
\text { (Expansive coupling) }\end{array}$ & $\begin{array}{l}-0.48 \\
\text { (Strong decoupling) }\end{array}$ \\
\hline 2009-2010 & $\begin{array}{c}0.64 \\
\text { (Weak decoupling) }\end{array}$ & $\begin{array}{c}0.75 \\
\text { (Weak decoupling) }\end{array}$ & $\begin{array}{c}0.74 \\
\text { (Weak decoupling) }\end{array}$ \\
\hline 2010-2011 & $\begin{array}{c}0.99 \\
\text { (Expansive coupling) }\end{array}$ & $\begin{array}{c}0.56 \\
\text { (Weak decoupling) }\end{array}$ & $\begin{array}{c}0.64 \\
\text { (Weak decoupling) }\end{array}$ \\
\hline 2011-2012 & $\begin{array}{c}0.28 \\
\text { (Weak decoupling) }\end{array}$ & $\begin{array}{c}0.30 \\
\text { (Weak decoupling) }\end{array}$ & $\begin{array}{c}0.21 \\
\text { (Weak decoupling) }\end{array}$ \\
\hline 2012-2013 & $\begin{array}{c}0.78 \\
\text { (Weak decoupling) }\end{array}$ & $\begin{array}{l}-1.32 \\
\text { (Strong decoupling) }\end{array}$ & $\begin{array}{c}0.09 \\
\text { (Weak decoupling) }\end{array}$ \\
\hline
\end{tabular}

During the study period, the decoupling state of Hebei was relatively stable; Hebei was in fact the best performing province. The decoupling states exhibited as weak decoupling during the 2005 to 2007 and 2009 to 2013 periods. That is, the transportation-related carbon emissions grew at the same time as the transportation sector's GDP was increasing. However, the increments of carbon emissions were less than the GDP in the transportation sector. 
The decoupling state of Beijing's transportation sector exhibited expansive negative decoupling during the 2005 to 2009 period. That is, with the economic growth in Beijing came increasingly significant environmental pressure. Then, the situation turned for the better, with alternately weak decoupling and expansive coupling present.

The decoupling of Tianjin can be roughly divided into two stages. The first phase was from 2005 to 2009, when Tianjin's decoupling state went from weak decoupling to strong decoupling to expansive negative decoupling. We can see that Tianjin's decoupling state was very unstable during this period. That is, the growth of Tianjin's economy was different to the growth rate of carbon emissions, and the degree of volatility was larger. The second phase was from during 2009 to 2013, when Tianjin's main decoupling state was always weak decoupling. That is, compared to the growth of Tianjin's economy, the growth rate of carbon emissions was slow. In the end, there was even a strong decoupling in Tianjin. This represents truly positive momentum in the development of Tianjin's transportation sector.

\subsection{Influencing Factors of Carbon Emissions from the Transportation Sector}

To disentangle these factors, we decompose the changes in transportation carbon emissions in BTH into five factors, according to Formulas (3) to (11). Then, we calculate the annual quantity of the influence of each factor. Furthermore, we obtain the cumulative effects of the various factors on transportation-related carbon emissions in BTH, as shown in Figures 4-6. The data in Figures 4-6 are not raw data. Firstly, we calculate the annual influence quantity of each factor according to Formula (3) to Formula (12). In addition, these formulas have been used combined with the carbon emissions of the ith fuel type (calculated by Formula (1)), the ith fuel type (the consumption of coal, gasoline, kerosene, diesel oil and fuel oil in transportation sector), GDP, total output value of transportation sector and total population of Beijing, Tianjin and Hebei. The source of these data is as shown in Section 3.2. Further, we get the cumulative effects of various factors to transportation carbon emissions in Beijing, Tianjin and Hebei according to the calculation results.

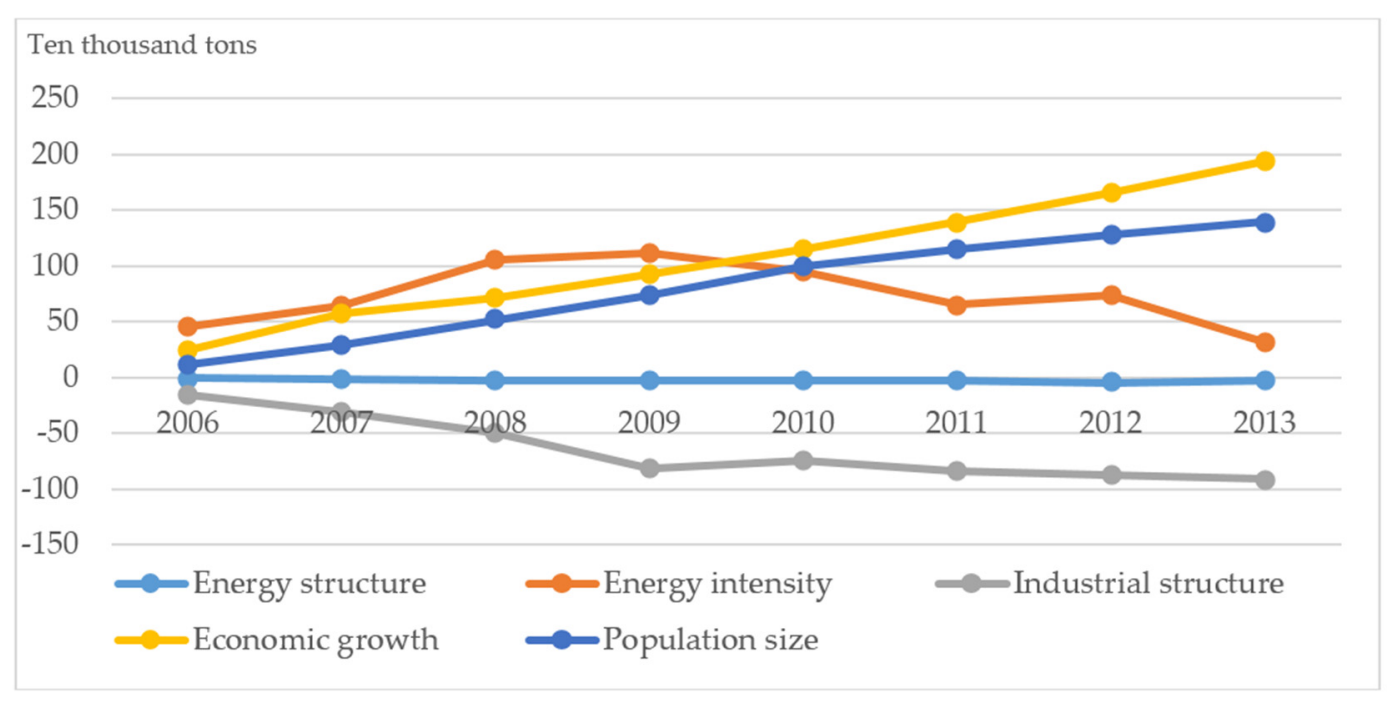

Figure 4. The cumulative effects of factors on carbon emission from transportation sector in Beijing. 


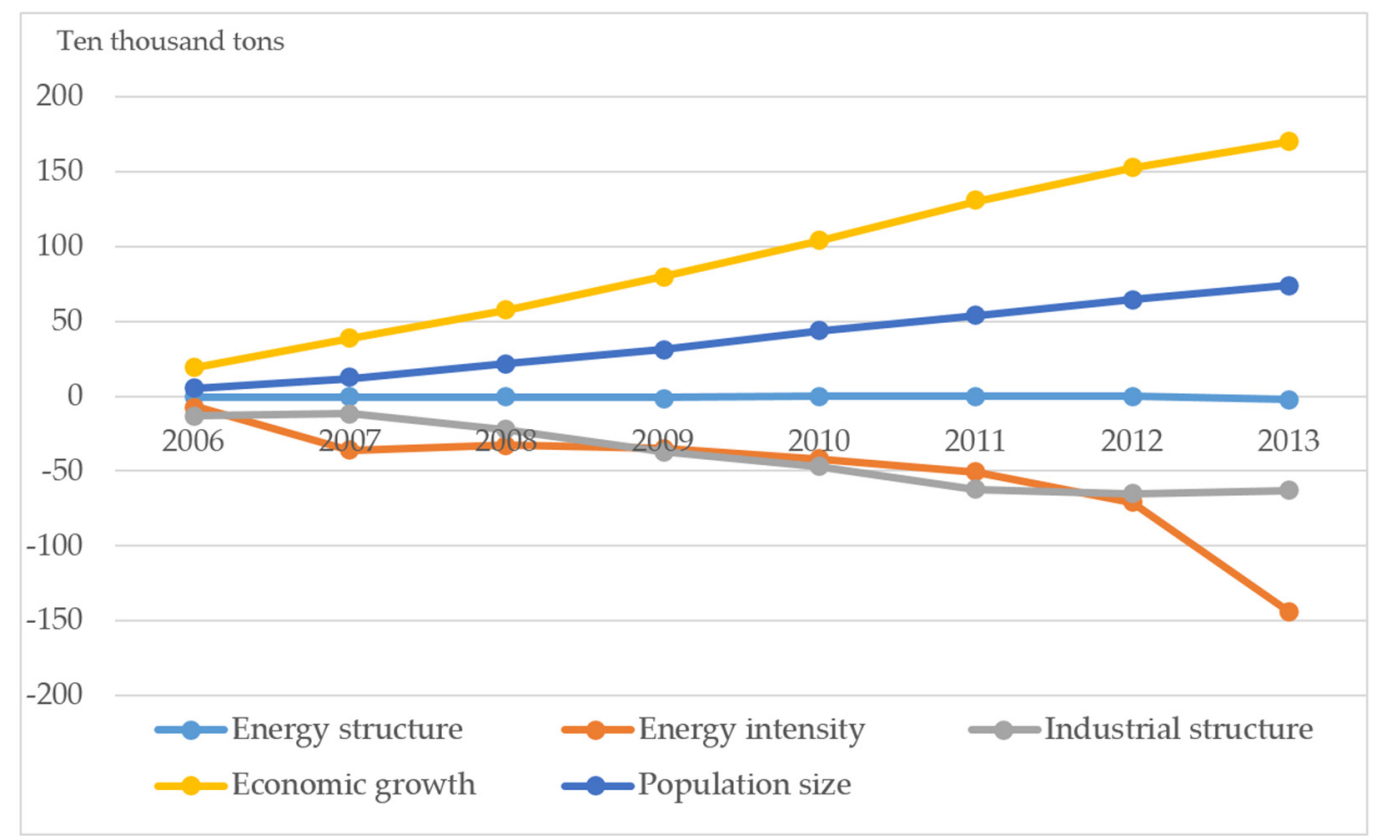

Figure 5. The cumulative effects of factors on carbon emission from transportation sector in Tianjin.

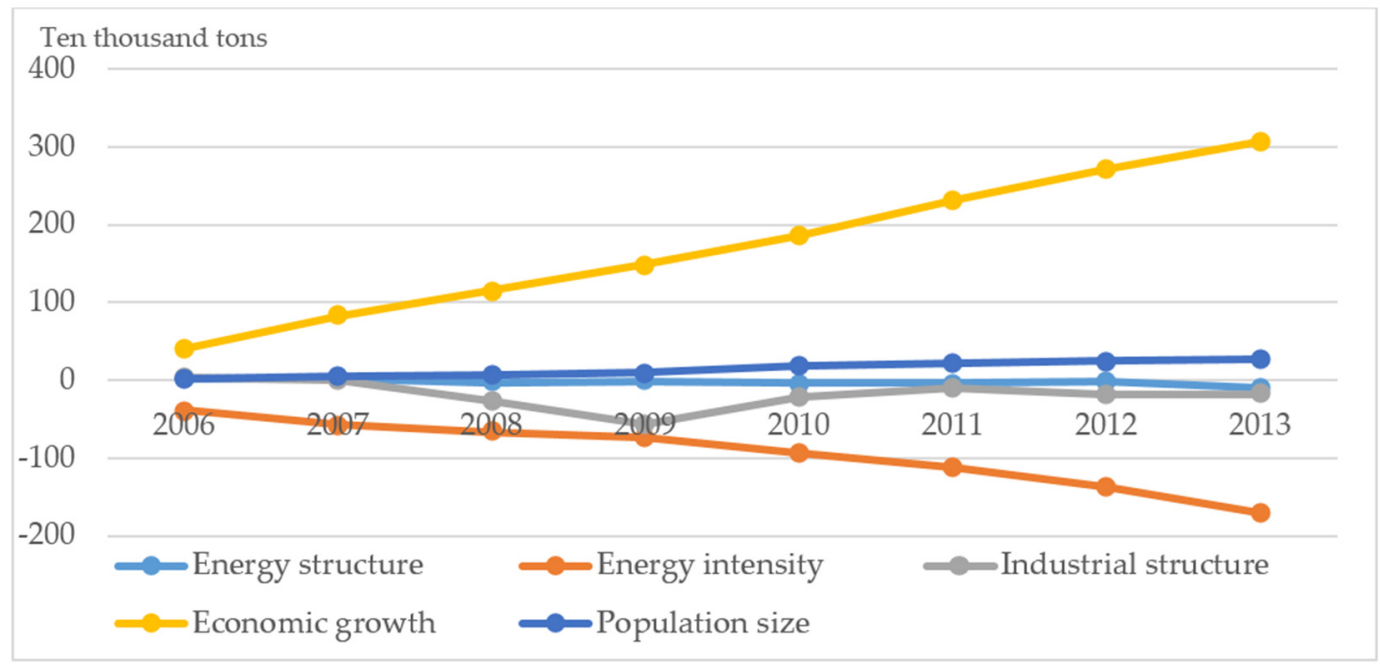

Figure 6. The cumulative effects of factors on carbon emission from transportation sector in Hebei.

A positive value indicates a positive influence on the increasing of carbon emissions. A negative value indicates a negative influence on the increasing of carbon emissions. The cumulative effect value of energy structure on transportation-related carbon emissions in BTH was negative during the study period. That is, energy structure plays a role in inhibiting transportation-related carbon emissions. This shows that the adjustment of energy structure in these three places has achieved positive results. However, the inhibitory effect is not significant. The result here is the same as the conclusions reached in previous studies conducted by the scholars mentioned earlier in this paper.

Figures 7-9 demonstrate the energy consumption in transportation as a percentage of coal, oil and natural gas in Beijing, Tianjin and Hebei, respectively. In general, we can conclude from these figures that the percentage of coal consumption of the transportation sector showed a decreasing trend in Beijing and Hebei during our study period, while the figures showed a fluctuating trend in Tianjin. During the 2007 to 2010 and 2011 to 2012 periods, the percentage of coal consumption increased, but the percentage of consumption decreased in other years. 


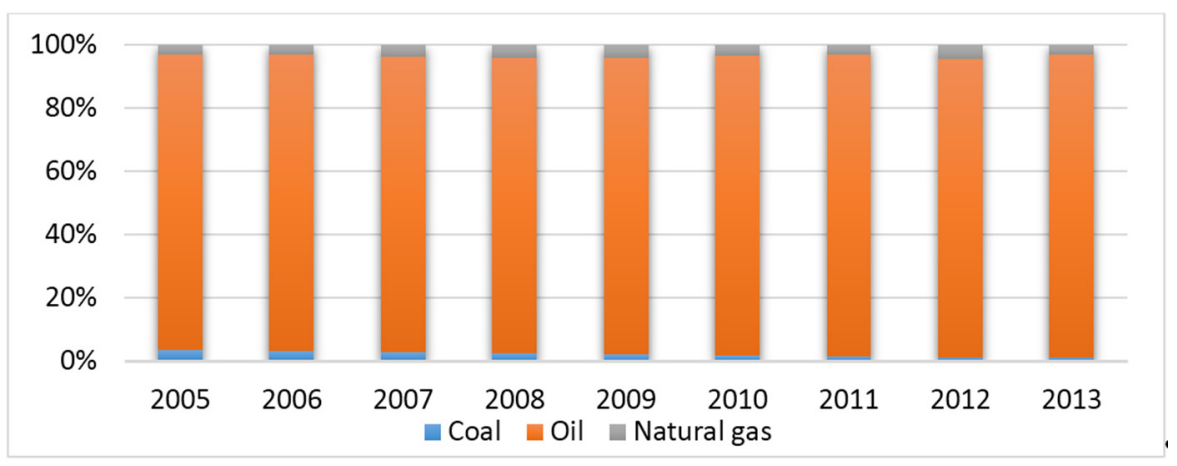

Figure 7. The percentage of different kinds of energy consumption in transportation in Beijing.

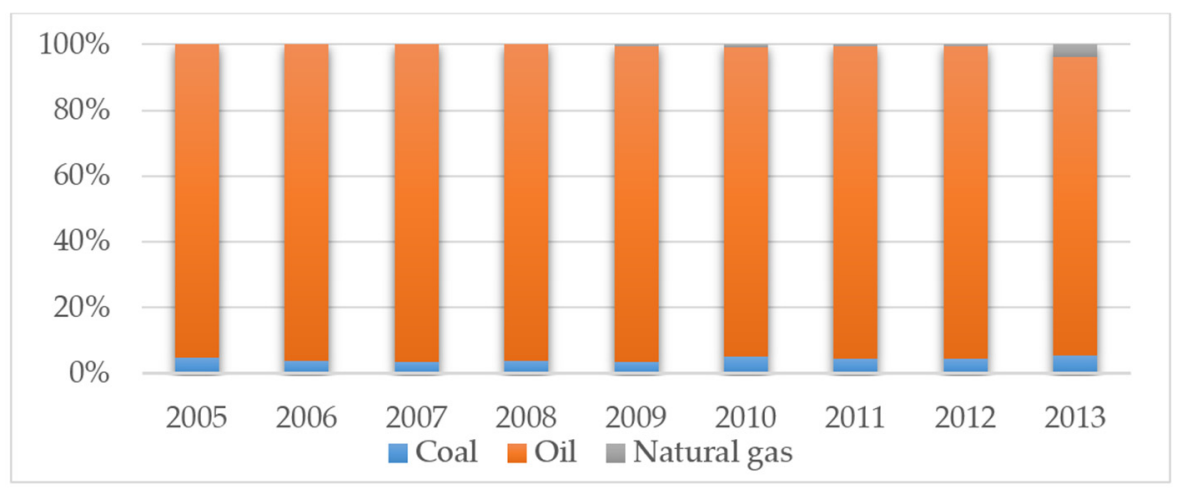

Figure 8. The percentage of different kinds of energy consumption in transportation in Tianjin.

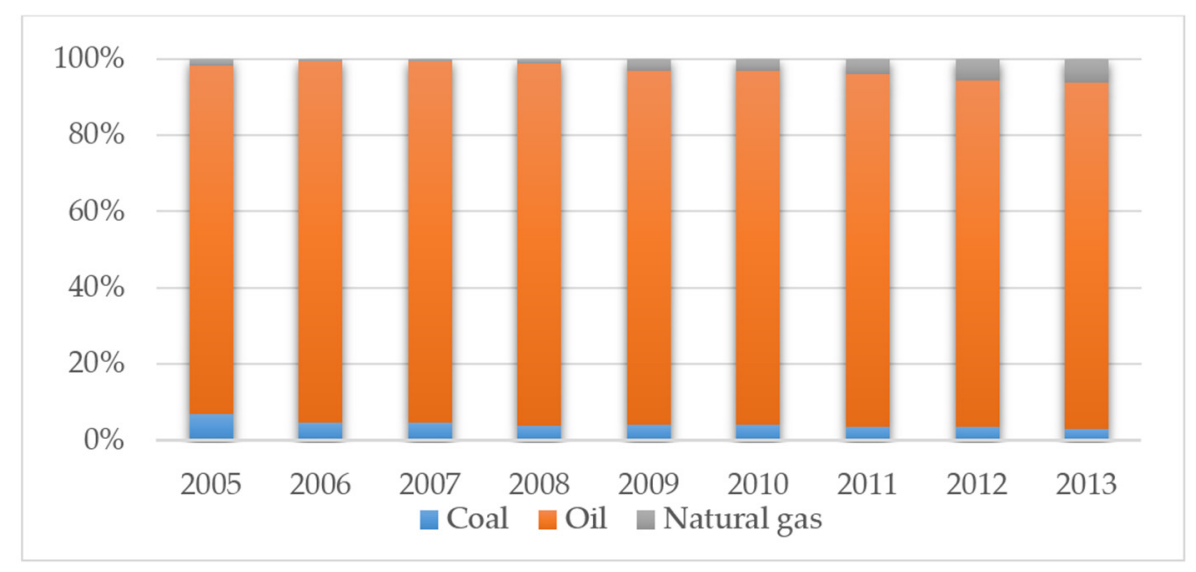

Figure 9. The percentage of different kinds of energy consumption in transportation in Hebei.

The percentage of natural gas consumption shows a decreasing trend in Tianjin and Hebei during our study period, while exhibiting a fluctuating trend in Beijing. During the 2005 to 2008 and 2011 to 2012 periods, coal consumption increased but also decreased in other years. Oil has remained the main energy type used in recent periods. Oil accounts for more than $90 \%$ of the energy consumption of the transportation sectors in BTH. This finding proves that the traditional oil-based energy structure is difficult to change in a short time.

Many earlier studies found that the decline in energy intensity has been the main factor associated with emissions deceleration in China [11,17,60]. For example, Dai et al. [16] concluded that improvements in energy intensity significantly inhibited the rise in energy use in China's logistics industry. This is a general trend, but we cannot rule out the regional differences. The effect of energy intensity on transportation-related carbon emissions in Tianjin and Hebei has been largely negative over 
the years. Nevertheless, the differences between Beijing and the other two areas covered by our study make it obvious that regional differences exist. The effect of energy intensity on transportation-related carbon emissions in Beijing was positive from 2006 to 2009, while the effect was negative from 2009 to 2013. This finding indicates that the Beijing's later efforts with regard to energy intensity were ultimately productive.

The cumulative effect value of energy intensity on transportation-related carbon emissions in Tianjin and Hebei were negative during our study period, while Beijing was positive. This finding indicates that energy consumption for each unit of GDP in the transportation sectors of Tianjin and Hebei are decreasing. During the study period, the GDP in the transportation sectors of Beijing, Tianjin and Hebei increase by $72 \%, 133 \%$, and $117 \%$, respectively. At the same time, the growth rate of transportation-related energy consumption in these places increased by $101 \%, 20 \%$, and $43 \%$. We can therefore see that the rate of transportation-related energy consumption has been less than the rate of GDP in the transportation sectors of Tianjin and Hebei in recent years. However, due to the rapid increase in the number of private cars in Beijing, the transportation-related energy consumption doubled in that city.

The previous research results mentioned in our literature review indicated that the optimization of tertiary industry structure played an inhibiting role with regard to transportation-related carbon emissions $[60,63]$. Given the actual situation, it is hard to adjust the industrial structure, so the industrial structure trend is not pronounced. The industrial structure has had an adverse effect on transportation-related carbon emissions in Tianjin and Hebei, and the effect is remarkable. The industrial structure contribution to carbon emissions in the BTH area is as shown in Figure 10. This figure demonstrates that the effect of industrial structure on transportation carbon emissions exhibited a fluctuating trend over the years, with alternating performances of inhibition and promotion. The curve of energy intensity effects on transportation-related carbon emission in Beijing and Hebei appears as a flat "W". For Beijing, the performance of energy intensity was promotion in 2009 and 2010, while acting as an inhibitor in the other years. Also, the degree of inhibition increased constantly from 2005 to 2009, then steadily decreased from 2010 to 2013. For Hebei, energy intensity's performance was promotion during the periods 2005 to 2006, 2009 to 2011 and 2012-2013, while playing an inhibition role in the other years covered by our study. For Tianjin, energy intensity's performance was promotion during 2006 to 2007 and 2012 to 2013, and inhibition in the other years covered by our study. However, these trends were not obvious. This is mainly due to the lack of any substantial technology revolution during the study period. The cumulative effect value of industrial structure on transportation carbon emissions in BTH was negative during the study period. These results show that industrial structure reform efforts have made some achievements.

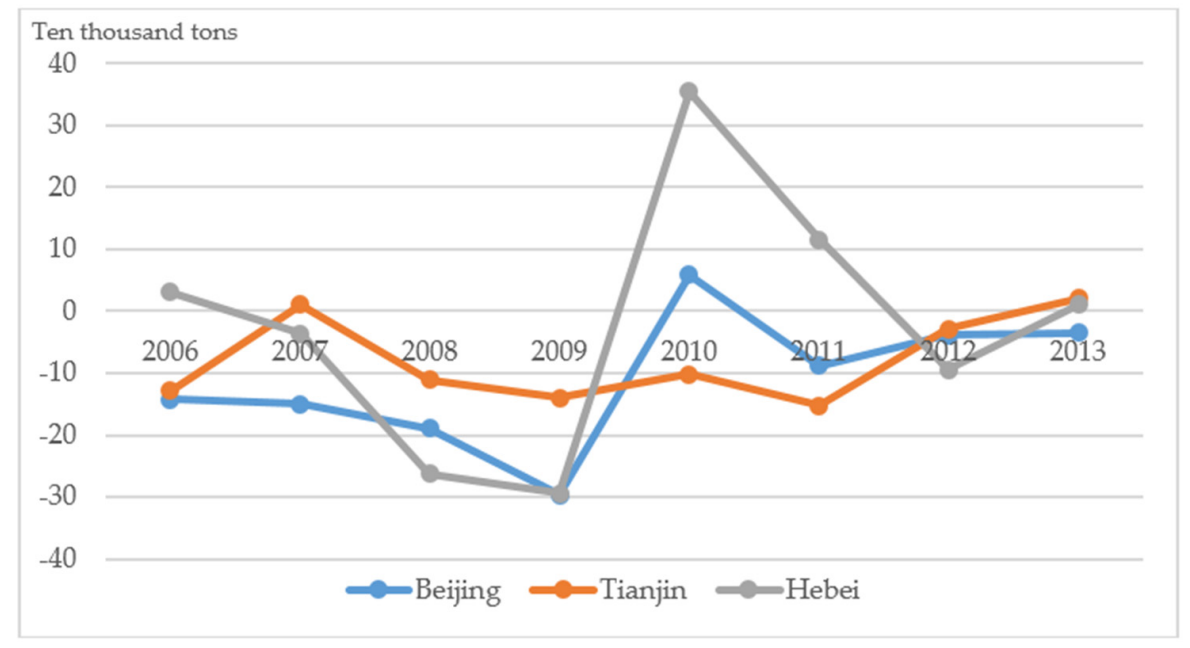

Figure 10. The industrial structure contributing to carbon emission in Beijing-Tianjin-Hebei area. 
As for economic growth, Houda Achour and Mounir Belloumi [14] et al. determined that economic growth is one of the most important contributory factors in the growth of carbon emissions. Similarly, economic growth has played a positive role in increasing the transportation-related carbon emissions of BTH over the years. Economic growth is also the most decisive promotional factor in the area's increase of carbon emissions. This finding is the same as was reached in other studies. The economic growth of the transportation sector has been accompanied by a corresponding increase in carbon emissions.

Population size has also played a positive role in increasing transportation-related carbon emissions over the years. Figure 11 demonstrated the growth rate of population in Beijing-Tianjin-Hebei area based on their annual population. The formula is expressed as follows:

$$
\text { growth rate }=\frac{\mathrm{P}(\mathrm{t})-\mathrm{P}(\mathrm{t}-1)}{\mathrm{P}(\mathrm{t}-1)}
$$

where $\mathrm{P}(\mathrm{t})$ denotes the population in year $\mathrm{t}, \mathrm{P}(\mathrm{t}-1)$ denotes the population in year $\mathrm{t}-1$.

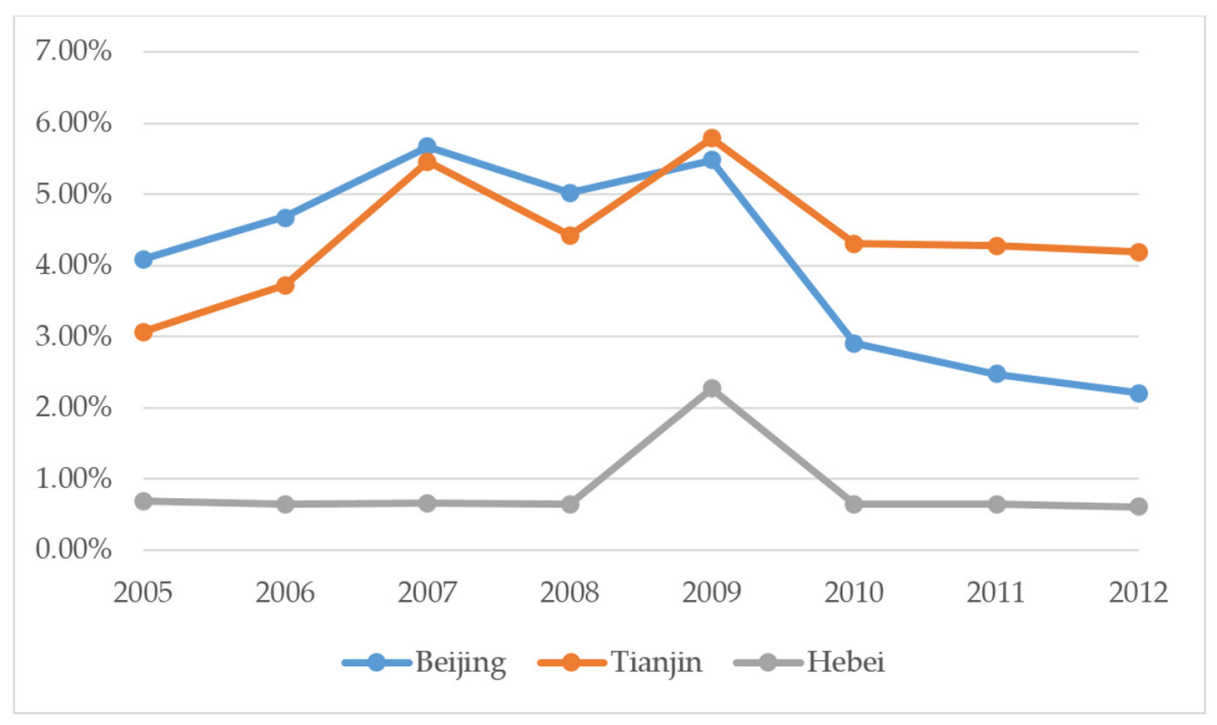

Figure 11. The growth rate of population in Beijing-Tianjin-Hebei area.

This finding is also consistent with those of most of the previous studies mentioned in this paper's literature review. Population size as a factor boosting the growth of transportation-related carbon emissions really cannot be ignored. However, the degree of influence is less than that of economic growth. From Figure 4 to Figure 6, we can see that the effect of population size on the levels of transportation-related carbon emissions has been very significant in Beijing but relatively small in Hebei. The reason for this finding can be found in Figure 11, which demonstrates the growth rate of population in the BTH area based on each region's annual population growth. The growth rate of the population in Hebei was $2.27 \%$ from 2008 to 2009. During that time, the population of Beijing grew at a relatively low rate of less than $1 \%$. However, the population growth rates of both Beijing and Hebei were significantly higher than that of Tianjin. Also, their growth rate curves appear as a flat "M". During the periods from 2007 to 2008 and 2009 to 2012, the population growth rates of Beijing and Tianjin decreased, but the rates increased in other years. This is probably because Beijing is the capital of our country, and large numbers of people from external populations flood into Beijing due to the city's political, economic, educational, welfare and other factors. Tianjin is the most important hub and port city of north China, with logistics as the key industry. Meanwhile, Tianjin has implemented a number of policies to support the development of high-tech industries. Therefore, Tianjin attracts a large number of talented individuals. The increase in population in each area led to a corresponding 
increase in the number of privately-owned cars. Thus, the energy consumption of the transportation sector (including private transportation) in Beijing and Tianjin has grown rapidly. Therefore, we can conclude that population size has had a significant effect on the levels of transportation-related carbon emissions in Beijing and Tianjin.

\section{Conclusions and Policy Implication}

Above all, we want to point to point out the limitation of this this research. Due to the limitations relating to data acquisition, in this paper, the minority conversion coefficients of the 2009 transportation sector GDP Indexes of Tianjin and Hebei are missing. We used the average annual growth rate of the known GDP Index to estimate the missing minority conversion coefficients of the 2009 GDP Indexes of Tianjin and Hebei. In the future, many aspects of this article require improvement. Firstly, we will update the analysis once we can acquire the minority conversion coefficients of the 2009 GDP Indexes of Tianjin and Hebei. Secondly, we intend to create a scenario analysis to forecast and explore the effects of the influencing factors and provide detailed policies to help reduce carbon emissions.

\subsection{Conclusions}

Based on the data relating to energy consumption and economic growth in the transportation sector in BTH from 2005 to 2013, we calculated the carbon emissions and the decoupling degree between carbon emissions and GDP in the transportation sector of these three places. Then, we analyzed the factors that influence the degrees of increases in carbon emission. The following conclusions can be drawn:

In combination with Figures 2 and 3, we can safely come to the conclusion that:

As one example, Tianjin's transportation sector GDP grew from 2012 to 2013, but the carbon emissions of Tianjin's transportation sector decreased during that time. Therefore, carbon emissions do not grow in line with transportation sector GDP. As another example, the output value of Hebei Province's transportation sector occupied first place during the period covered by our study, but the carbon emissions of Hebei's transportation sector was in second place. Therefore, we can conclude that it is not always the case that higher output produces more carbon emission in the transportation sector. Both of these two examples show that the coupling relationship between economic growth and carbon emissions is one of breakdown.

During the study period, Hebei was the best performing province. The decoupling relationship between carbon emissions and GDP in Hebei's transportation sector was relatively stable. The decoupling state was mainly one of weak decoupling. The decoupling state of Beijing's transportation sector presented mainly as expansive negative decoupling during the 2005 to 2009 period. Then, the situation took a turn for the better, alternating between weak decoupling and expansive decoupling. The decoupling states of Tianjin can be roughly divided into two stages. The first phase was from 2005 to 2009, when Tianjin's decoupling state was very unstable and largely volatile. The second phase was from 2009 to 2013, when the main decoupling state was always weak decoupling. In the end, Tianjin even experienced strong decoupling. This is evidence of really good momentum in the development of the transportation sector.

Energy structure plays a role in inhibiting transportation-related carbon emissions. However, the inhibitory effect is not significant. Economic growth and population size played positive roles in increasing transportation-related carbon emissions over the years. The effect of energy intensity on transportation-related carbon emissions in Tianjin and Hebei was negative over the years covered by our study period. Nevertheless, significant differences were obvious between Beijing and those other two places. Obvious regional differences were displayed. The effect of energy intensity on transportation-related carbon emissions in Beijing was negative from 2006 to 2009, then positive from 2009 to 2013. The later emission reduction efforts made by Beijing are proving to be productive. Industrial structure had an adverse effect on transportation-related carbon emissions in Tianjin and Hebei during the study period, and the effect is remarkable. The effect of energy intensity 
on transportation-related carbon emissions exhibited a fluctuating trend over the years, alternating between performances of inhibition and promotion. The cumulative effect value of industrial structure on transportation-related carbon emissions in BTH was negative during the study period. The results show that the reform of industrial structure reform has made some positive achievements.

\subsection{Policy Implication}

According to the above conclusions and considering the actual demands for transportation in BTH, we suggest the following major measures to save energy and reduce carbon emissions (Figure 12).

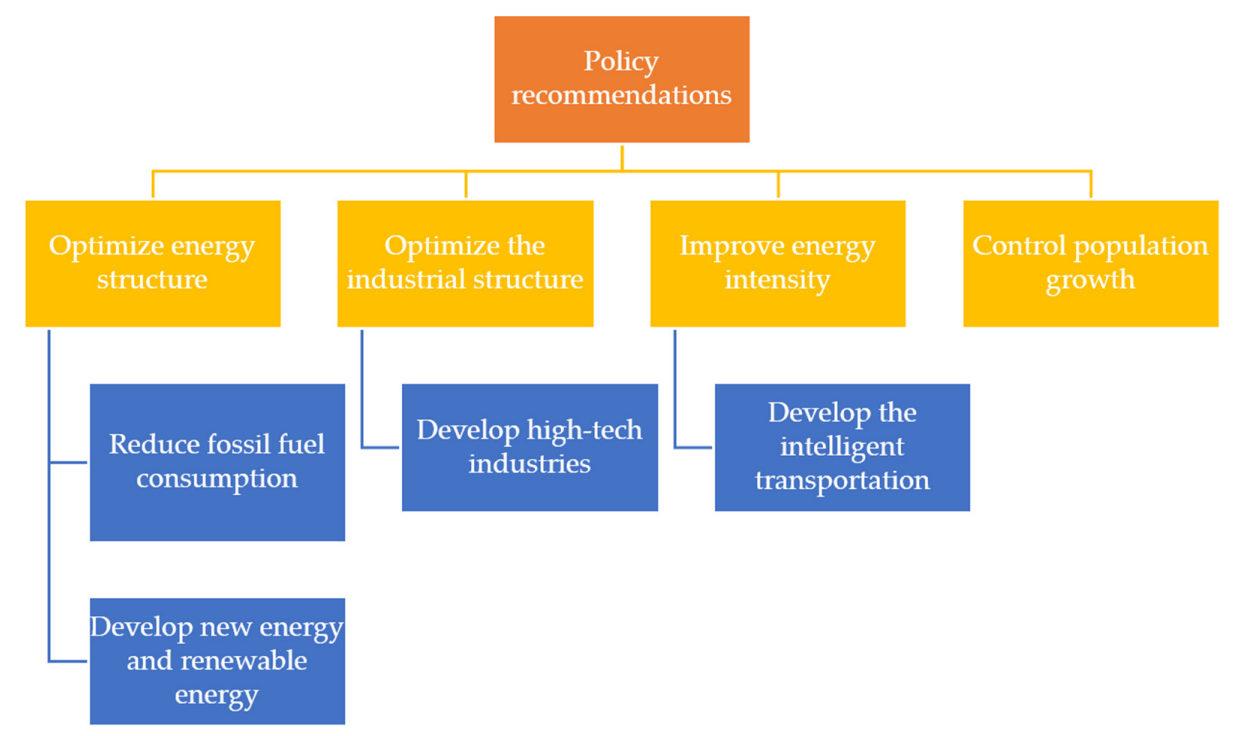

Figure 12. The suggestions based on the data analysis.

(1) Optimizing the industrial structure. According to the study on the influence of industrial structure to transportation energy consumption conducted by Wang et al. [83], with China entering the late stage of industrialization, the influence exerted by adjusting the industrial structure will become more and more obvious in terms of transportation energy consumption. The adjustment of industrial structure in Beijing, Tianjin and Hebei has got great feedback, especially for Tianjin, the cumulative carbon emission caused by industrial structure is $-182.66 \%$ of the total cumulative carbon emission during 2005-2013. Beijing and Hebei is $-33.61 \%$ and $-12.84 \%$ respectively. Therefore, we should continue to optimize and adjust the industrial structure, speed up the adjustment and pace of that industrial structure, vigorously develop high-tech industries, and promote the transformation of industrial structure to become advanced and reasonable;

(2) Optimizing energy structure. We can develop new energy sources and renewable energy to optimize the country's energy structure, thereby reducing the carbon emissions of the transportation sector. The use of clean energy and reducing dependence on fossil fuels should be encouraged;

(3) Improving energy efficiency. The government should introduce policies and establish financial support systems to promote the development of low-carbon technologies. In order to address the issue of transportation-related carbon emission, we can develop intelligent transportation and introduce networking, cloud computing and other new-generation technology into the transportation sector. Of course, due to the literature and author knowledge limitations, the influencing factors of transportation-related carbon emissions in BTH are not decomposed or detailed enough; 
(4) Controlling population growth: Beijing and Tianjin is the economic axis of enclosed Bohai Sea, which attracted migrants from across the country. Therefore, it is necessary to make some policies to control the population. Especially for Tianjin, its growth rate of population is always more than $4 \%$.

Acknowledgments: The current work is supported by "the Fundamental Research Funds for the Central Universities" (27R1706019B) and the Recruitment Talent Fund of China University of Petroleum (Huadong) (05Y16060020). We have received the grants in support of our research work. The funds we have received for covering the costs to publish in open access.

Author Contributions: Xiaoping Zhu conceived and designed the experiments and wrote the paper; Rongrong Li performed the experiments, analyzed the data and contributed reagents/materials/analysis tools and selected the data. All authors read and approved the final manuscript.

Conflicts of Interest: The authors declare no conflict of interest.

\section{References}

1. Adom, P.K.; Bekoe, W.; Amuakwa-Mensah, F.; Mensah, J.T.; Botchway, E. Carbon dioxide emissions, economic growth, industrial structure, and technical efficiency: Empirical evidence from Ghana, Senegal, and Morocco on the causal dynamics. Energy 2012, 47, 314-325. [CrossRef]

2. Garcia, E.; Martinez-Iglesias, M. Towards the Post-Carbon Society: Searching for Signs of the Transition and Identifying Obstacles. In Transitioning to a Post-Carbon Society; Springer: Berlin, Germany, 2017; pp. 314-325.

3. Krasting, J.; Dunne, J.; Stouffer, R.; Hallberg, R. Enhanced Atlantic sea-level rise relative to the Pacific under high carbon emission rates. Nat. Geosci. 2016, 9, 210-214. [CrossRef]

4. Wang, Q. Cheaper Oil—Challenge and Opportunity for Climate Change. Environ. Sci. Technol. 2015, 49, 1997-1998. [CrossRef] [PubMed]

5. Allen, S.K.; Plattner, G.K.; Nauels, A.; Xia, Y.; Stocker, T.F. Climate Change 2013: The Physical Science Basis. An overview of the Working Group 1 contribution to the Fifth Assessment Report of the Intergovernmental Panel on Climate Change (IPCC). Available online: http://www.ipcc.ch/report/ar5/wg1/ (accessed on 22 April 2017).

6. Balat, M.; Balat, H. Recent trends in global production and utilization of bio-ethanol fuel. Appl. Energy 2009, 86, 2273-2282. [CrossRef]

7. OECD. Strategies to reduce greenhouse gas emissions from road transport: Analytical methods. Available online: http://www.internationaltransportforum.org/Pub/pdf/02GreenhouseE.pdf (accessed on 22 April 2017).

8. Wang, Q.; Jiang, X.-T.; Li, R. Comparative decoupling analysis of energy-related carbon emission from electric output of electricity sector in Shandong Province, China. Energy 2017, 127, 78-88. [CrossRef]

9. Wang, Q.; Li, R.; Jiang, R. Decoupling and Decomposition Analysis of Carbon Emissions from Industry: A Case Study from China. Sustainability 2016, 8, 1059. [CrossRef]

10. Wang, Q.; Li, R. Cheaper Oil: A turning point in Paris climate talk? Renew. Sustain. Energy Rev. 2015, 52, 1186-1192. [CrossRef]

11. Wang, Q.; Chen, X. Energy policies for managing China's carbon emission. Renew. Sustain. Energy Rev. 2015, 50, 470-479. [CrossRef]

12. Wang, Q.; Li, R. Impact of cheaper oil on economic system and climate change: A SWOT analysis. Renew. Sustain. Energy Rev. 2016, 54, 925-931. [CrossRef]

13. Wang, Q.; Li, R. Journey to burning half of global coal: Trajectory and drivers of China's coal use. Renew. Sustain. Energy Rev. 2016, 58, 341-346. [CrossRef]

14. Achour, H.; Belloumi, M. Decomposing the influencing factors of energy consumption in Tunisian transportation sector using the LMDI method. Transp. Policy 2016, 52, 64-71. [CrossRef]

15. Yin, P.; .Duan, P.L.; Chen, C. The canbon emission pattern and the relationship with economic growth in transportation industry of China. J. Arid Land Resour. Environ. 2016, 30, 7-12.

16. Dai, Y.; Gao, H.O. Energy consumption in China's logistics industry: A decomposition analysis using the LMDI approach. Transp. Res. Part D 2016, 46, 69-80. [CrossRef]

17. Lin, B.; Benjamin, N.I. Influencing factors on carbon emissions in China transport industry. A new evidence from quantile regression analysis. J. Clean. Prod. 2017, 150, 175-187. [CrossRef] 
18. $\mathrm{Xu}, \mathrm{B}$; ; Lin, B. Factors affecting carbon dioxide $\left(\mathrm{CO}_{2}\right)$ emissions in China's transport sector: A dynamic nonparametric additive regression model. J. Clean. Prod. 2015, 101, 311-322. [CrossRef]

19. Lang, J.; Cheng, S.; Wei, W.; Zhou, Y.; Wei, X.; Chen, D. A study on the trends of vehicular emissions in the Beijing-Tianjin-Hebei (BTH) region, China. Atmos. Environ. 2012, 62, 605-614. [CrossRef]

20. Tan, M.; Li, X.; Xie, H.; Lu, C. Urban land expansion and arable land loss in China-A case study of Beijing-Tianjin-Hebei region. Land Use Policy 2005, 22, 187-196. [CrossRef]

21. Bilal, M.; Nichol, J.E. Evaluation of MODIS aerosol retrieval algorithms over the Beijing-Tianjin-Hebei region during low to very high pollution events. J. Geophys. Res. Atmos. 2015, 120, 7941-7957. [CrossRef]

22. National Bureau of Statistics of China. China Statistical Yearbook; China Statistics Press: Beijing, China, 2011. (In Chinese)

23. Searchinger, T.; Heimlich, R.; Houghton, R.A.; Dong, F.; Elobeid, A.; Fabiosa, J.; Tokgoz, S.; Hayes, D.; $\mathrm{Yu}, \mathrm{T}$.-H. Use of US croplands for biofuels increases greenhouse gases through emissions from land-use change. Science 2008, 319, 1238-1240. [CrossRef] [PubMed]

24. Houghton, R.; Hackler, J.; Lawrence, K. The US carbon budget: Contributions from land-use change. Science 1999, 285, 574-578. [CrossRef] [PubMed]

25. Fargione, J.; Hill, J.; Tilman, D.; Polasky, S.; Hawthorne, P. Land clearing and the biofuel carbon debt. Science 2008, 319, 1235-1238. [CrossRef] [PubMed]

26. Hertel, T.W.; Golub, A.A.; Jones, A.D.; O'Hare, M.; Plevin, R.J.; Kammen, D.M. Effects of US maize ethanol on global land use and greenhouse gas emissions: Estimating market-mediated responses. BioScience 2010, 60, 223-231. [CrossRef]

27. Lal, R. Carbon emission from farm operations. Environ. Int. 2004, 30, 981-990. [CrossRef] [PubMed]

28. McCarl, B.A.; Schneider, U.A. Greenhouse gas mitigation in US agriculture and forestry. Science 2001, 294, 2481-2482. [CrossRef] [PubMed]

29. Weber, C.L.; Matthews, H.S. Embodied environmental emissions in US international trade, 1997-2004. Environ. Sci. Technol. 2007, 41, 4875-4881. [PubMed]

30. Lugauer, S.; Jensen, R.; Sadler, C. An estimate of the age distribution's effect on carbon dioxide emissions. Econ. Inq. 2014, 52, 914-929. [CrossRef]

31. Friedl, B.; Getzner, M. Determinants of $\mathrm{CO}_{2}$ emissions in a small open economy. Ecol. Econ. 2003, 45, $133-148$. [CrossRef]

32. Wei, C.; Ni, J.; Du, L. Regional allocation of carbon dioxide abatement in China. China Econ. Rev. 2012, 23, 552-565. [CrossRef]

33. Yang, B.; Liu, C.; Su, Y.; Jing, X. The Allocation of Carbon Intensity Reduction Target by 2020 among Industrial Sectors in China. Sustainability 2017, 9, 148. [CrossRef]

34. Wang, Q. China has the capacity to lead in carbon trading. Nature 2013, 493, 273. [CrossRef] [PubMed]

35. Wang, Q. China needs workers more than academics. Nature 2013, 499, 381. [CrossRef] [PubMed]

36. Wang, Q. China should aim for a total cap on emissions. Nature 2014, 512, 115. [CrossRef] [PubMed]

37. Wang, Q. China's citizens must act to save their environment. Nature 2013, 497, 159. [CrossRef] [PubMed]

38. Wang, Q.; Li, R.; Liao, H. Toward Decoupling: Growing GDP without Growing Carbon Emissions. Environ. Sci. Technol. 2016, 50, 11435-11436. [CrossRef] [PubMed]

39. Wang, F.; Wang, C.; Su, Y.; Jin, L.; Wang, Y.; Zhang, X. Decomposition Analysis of Carbon Emission Factors from Energy Consumption in Guangdong Province from 1990 to 2014. Sustainability 2017, 9, 274. [CrossRef]

40. Chandran, V.; Tang, C.F. The impacts of transport energy consumption, foreign direct investment and income on $\mathrm{CO}_{2}$ emissions in ASEAN-5 economies. Renew. Sustain. Energy Rev. 2013, 24, 445-453. [CrossRef]

41. Azlina, A.; Law, S.H.; Mustapha, N.H.N. Dynamic linkages among transport energy consumption, income and $\mathrm{CO}_{2}$ emission in Malaysia. Energy Policy 2014, 73, 598-606. [CrossRef]

42. Ong, H.; Mahlia, T.; Masjuki, H. A review on energy pattern and policy for transportation sector in Malaysia. Renew. Sustain. Energy Rev. 2012, 16, 532-542. [CrossRef]

43. Steenhof, P.; Woudsma, C.; Sparling, E. Greenhouse gas emissions and the surface transport of freight in Canada. Transp. Res. Part D 2006, 11, 369-376. [CrossRef]

44. Mazzarino, M. The economics of the greenhouse effect: Evaluating the climate change impact due to the transport sector in Italy. Energy Policy 2000, 28, 957-966. [CrossRef]

45. Mraihi, R.; ben Abdallah, K.; Abid, M. Road transport-related energy consumption: Analysis of driving factors in Tunisia. Energy Policy 2013, 62, 247-253. [CrossRef] 
46. Ang, J.B. $\mathrm{CO}_{2}$ emissions, energy consumption, and output in France. Energy Policy 2007, 35, 4772-4778. [CrossRef]

47. Menyah, K.; Wolde-Rufael, Y. Energy consumption, pollutant emissions and economic growth in South Africa. Energy Econ. 2010, 32, 1374-1382. [CrossRef]

48. Ozturk, I.; Acaravci, A. $\mathrm{CO}_{2}$ emissions, energy consumption and economic growth in Turkey. Renew. Sustain. Energy Rev. 2010, 14, 3220-3225. [CrossRef]

49. Azlina, A.; Mustapha, N.N. Energy, economic growth and pollutant emissions nexus: The case of Malaysia. Procedia-Soc. Behav. Sci. 2012, 65, 1-7. [CrossRef]

50. Wang, Q.; Chen, X. China's electricity market-oriented reform: From an absolute to a relative monopoly. Energy Policy 2012, 51, 143-148. [CrossRef]

51. Wang, Q.; Li, R. Drivers for energy consumption: A comparative analysis of China and India. Renew. Sustain. Energy Rev. 2016, 62, 954-962. [CrossRef]

52. Wang, Q. Nuclear safety lies in greater transparency. Nature 2013, 494, 403. [CrossRef] [PubMed]

53. Wang, Q.; Li, R. Sino-Venezuelan oil-for-loan deal - the Chinese strategic gamble?\#. Renew. Sustain. Energy Rev. 2016, 64, 817-822.

54. Zhang, M.; Li, H.; Zhou, M.; Mu, H. Decomposition analysis of energy consumption in Chinese transportation sector. Appl. Energy 2011, 88, 2279-2285. [CrossRef]

55. Huang, J.; Yang, X.; Cheng, G.; Wang, S. A comprehensive eco-efficiency model and dynamics of regional eco-efficiency in China. J. Clean. Prod. 2014, 67, 228-238. [CrossRef]

56. Qipeng, S.; Jiao, J.; Cheng, X. Energy Consumption Driving Factors and Measuring Models of Regional Integrated Transport System. J. Transp. Syst. Eng. Inf. Technol. 2013, 13, 1-9.

57. Ma, C.; Stern, D.I. China's changing energy intensity trend: A decomposition analysis. Energy Econ. 2008, 30, 1037-1053. [CrossRef]

58. Zhao, M.; Tan, L.; Zhang, W.; Ji, M.; Liu, Y.; Yu, L. Decomposing the influencing factors of industrial carbon emissions in Shanghai using the LMDI method. Energy 2010, 35, 2505-2510. [CrossRef]

59. Wang, Q. Effective policies for renewable energy-The example of China's wind power-lessons for China's photovoltaic power. Renew. Sustain. Energy Rev. 2010, 14, 702-712. [CrossRef]

60. Wang, Q.; Chen, X.; Jha, A.N.; Rogers, H. Natural gas from shale formation-the evolution, evidences and challenges of shale gas revolution in United States. Renew. Sustain. Energy Rev. 2014, 30, 1-28. [CrossRef]

61. Wang, Q.; Li, R. Research status of shale gas: A review. Renew. Sustain. Energy Rev. 2017, 74, 715-720. [CrossRef]

62. Wang, Q.; Li, R. Natural gas from shale formation: A research profile. Renew. Sustain. Energy Rev. 2016, 57, 1-6. [CrossRef]

63. Zhao, Y.; Kuang, Y.; Huang, N. Decomposition Analysis in Decoupling Transport Output from Carbon Emissions in Guangdong Province, China. Energies 2016, 9, 295. [CrossRef]

64. Kaya, Y. Impact of Carbon Dioxide Emission Control on GNP Growth: Interpretation of Proposed Scenarios. In Procceding of the IPCC Energy and Industry Subgroup, Response Strategies Working Group, Paris, France, 1990.

65. Yang, L.-J.; Wu, W.; Su, Q.; Du, Z.-P.; Jiang, X.-W. Carbon emissions of transportation energy consumption and its decoupling analysis in JiangSu Province. Resour. Environ. Yangtze Basin 2014, 23, 1383-1390.

66. Sgouridis, S.; Bonnefoy, P.A.; Hansman, R.J. Air transportation in a carbon constrained world: Long-term dynamics of policies and strategies for mitigating the carbon footprint of commercial aviation. Transp. Res. Part A Policy Pract. 2011, 45, 1077-1091. [CrossRef]

67. United States Agency for International Development. GHG Protocol Tool For Energy Consumption in China; World Resources Institute: Washington, DC, USA, 2013.

68. Gray, D.; Anable, J.; Illingworth, L.; Graham, W. Decoupling the link between economic growth, transport growth and carbon emissions in Scotland. Available online: https:/ / www.researchgate.net/publication/ 267221393 (accessed on 22 April 2017).

69. Aiwen, Z.; Dong, L. Empirical Analysis on Decoupling Relationship Between Carbon Emission and Economic Growth in China. Technol. Econ. 2013, 1, 019.

70. Tapio, P. Towards a theory of decoupling: Degrees of decoupling in the EU and the case of road traffic in Finland between 1970 and 2001. Transp. Policy 2005, 12, 137-151. [CrossRef] 
71. Hinterberger, F.; Schmidt-Bleek, F. FORUM: Dematerialization, MIPS and Factor 10 Physical sustainability indicators as a social device. Ecol. Econ. 1999, 29, 53-56. [CrossRef]

72. Lu, J.F.; Hui, F.; Wang, X.X. Study on the influencing factors of regional transportation carbon emission efficiency. Transp. Syst. Eng. Inf. 2016, 16, 25-30.

73. Ang, B.; Choi, K.-H. Decomposition of aggregate energy and gas emission intensities for industry: A refined Divisia index method. Energy J. 1997, 18, 59-73. [CrossRef]

74. Ang, B.; Liu, N. Energy decomposition analysis: IEA model versus other methods. Energy Policy 2007, 35, 1426-1432. [CrossRef]

75. Ang, B.W. Decomposition analysis for policymaking in energy: Which is the preferred method? Energy Policy 2004, 32, 1131-1139. [CrossRef]

76. Ang, B.W. The LMDI approach to decomposition analysis: A practical guide. Energy Policy 2005, 33, 867-871. [CrossRef]

77. Ang, B.W. LMDI decomposition approach: A guide for implementation. Energy Policy 2015, 86, $233-238$. [CrossRef]

78. Ang, B.W.; Liu, F.; Chew, E.P. Perfect decomposition techniques in energy and environmental analysis. Energy Policy 2003, 31, 1561-1566. [CrossRef]

79. Ang, B.W.; Su, B. Carbon emission intensity in electricity production: A global analysis. Energy Policy 2016, 94, 56-63. [CrossRef]

80. China Statistics Press. China Energy Statistical Yearbook; China Statistics Press: Beijing, China, 2005. (In Chinese)

81. China Statistics Press. China Energy Statistical Yearbook; China Statistics Press: Beijing, China, 2010. (In Chinese)

82. China Statistics Press. China Energy Statistical Yearbook; China Statistics Press: Beijing, China, 2013. (In Chinese)

83. Wang, J.W.; Lui, X.Y.; Gao, J. The influence of industrial structure adjustment on transportation energy consumption. J. Chang'an Univ. (Soc. Sci. Ed.) 2011, 13, 28-31.

(C) 2017 by the authors. Licensee MDPI, Basel, Switzerland. This article is an open access article distributed under the terms and conditions of the Creative Commons Attribution (CC BY) license (http:/ / creativecommons.org/licenses/by/4.0/). 